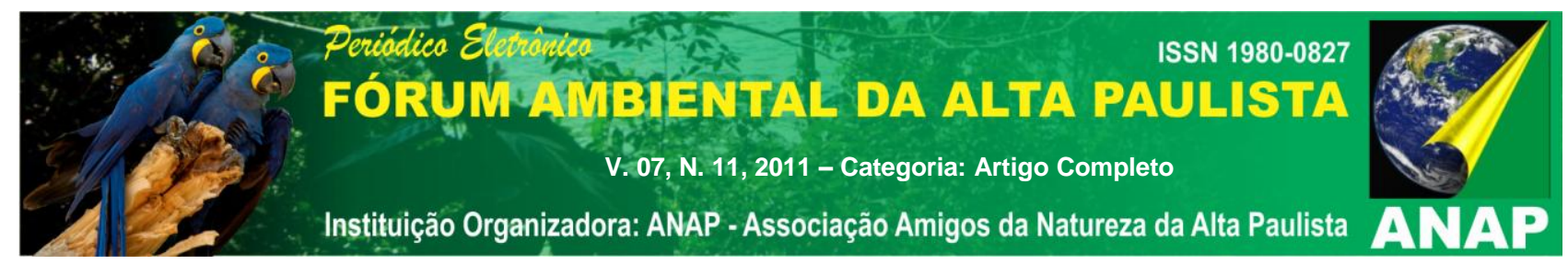

\title{
AVALIAÇÃO DOS ASPECTOS E IMPACTOS AMBIENTAIS EM UM PROCESSO INDUSTRIAL DE UMA DESTILARIA
}

Talita Nascimento de Menezes ${ }^{1}$

\author{
Renata Ribeiro de Araújoº
}

Stela Amaral Gonçalves ${ }^{3}$

\begin{abstract}
RESUMO: A finalidade geral do sistema de gestão ambiental é equilibrar a proteção ambiental e a prevenção de poluição com as necessidades econômicas das organizações. As empresas do setor sucroalcooleiro, produtoras de açúcar e álcool, desenvolvem atividades que podem impactar o meio ambiente, portanto é que se recomenda a utilização de um sistema de gestão ambiental para as empresas do setor. Este trabalho apresenta a identificação e classificação dos aspectos e impactos ambientais decorrentes do processo industrial em um estudo de caso em uma Destilaria, utilizando como referência a aplicação da legislação ambiental e a avaliação dos impactos ambientais mais significativos, de acordo com metodologia descrita por Moreira (2006), para propor ações corretivas e preventivas no processo industrial da organização.
\end{abstract}

Palavras-chave: Impactos Ambientais. Sistema de Gestão Ambiental. Destilaria.

\section{Introdução}

O setor sucroalcooleiro brasileiro abrange as empresas que produzem açúcar ou álcool, ou atuam em algum elo da cadeia produtiva desses elementos. No Brasil, esse setor está diretamente relacionado às culturas de cana-deaçúcar, uma vez que este é o principal insumo para os processos produtivos.

O uso intensivo da cana-de-açúcar como elemento de base para a produção do açúcar e do álcool, aliado à condição climática e outros fatores ambientais, confere diversos diferenciais à produtividade e à qualidade dos produtos brasileiros frente a alternativas estrangeiras, as quais se utilizam de outros insumos, como o milho ou a beterraba.

No Brasil, a plantação de cana é feita nas regiões Centro-Sul e NorteNordeste, o que permite produção o ano todo visto que existem dois períodos de safra: de maio a novembro na região centro-sul e de setembro a março na região norte-nordeste. 
A estrutura atual do setor iniciou sua formação em 1975, com o lançamento do Programa Nacional do Álcool (Proálcool), que tinha o objetivo de reduzir a dependência energética do país a partir de grandes investimentos na produção e subsídios ao desenvolvimento de um mercado consumidor do álcool. Com a segunda crise do petróleo, em 1979, e o desenvolvimento da engenharia nacional, surgiram os motores preparados para trabalhar exclusivamente com o álcool hidratado.

Com o fim da regulamentação governamental, iniciou-se o regime de livre mercado, sem subsídios, com os preços do açúcar e álcool passando a ser definidos conforme as oscilações de oferta e demanda. Assim, os preços da cana passaram a depender de sua qualidade e da sua participação porcentual nos produtos finais.

Para gerenciar e equilibrar produção e demandas setoriais, a iniciativa privada tem procurado criar instrumentos de mercado, como operações futuras, e desenvolver novas oportunidades para o açúcar e álcool.

Além dos aspectos econômicos, devem ser mencionados os aspectos sociais (geração de empregos) e ambientais (preocupação ambiental com a utilização de combustíveis renováveis e limpos) que também impulsionam de forma decisiva o crescimento do setor.

A implantação de sistemas de gestão ambiental é atualmente uma ferramenta essencial para o setor sucroalcooleiro, pois desenvolve a responsabilidade com a sociedade e com a preservação do meio ambiente, sem deixar de considerar o crescimento econômico.

De acordo com uma das normas de gestão ambiental mais conhecida, ISO 14001, as normas de gestão ambiental têm por objetivo prover as organizações um sistema da gestão ambiental eficaz que possam ser integrados a outros requisitos da gestão, e auxiliá-las a alcançar seus objetivos ambientais e econômicos.

Diante do exposto, o presente trabalho desenvolveu um estudo no processo produtivo de uma Destilaria, para uma possível implantação do sistema de gestão ambiental na indústria, de acordo com a ISO 14001 (2004). Desta forma, o objetivo geral foi a identificação e classificação dos aspectos e impactos ambientais causados pela atividade industrial da Destilaria, utilizando a legislação ambiental brasileira como valores de referência, buscando a melhoria contínua do processo industrial e a conservação do meio ambiente. 


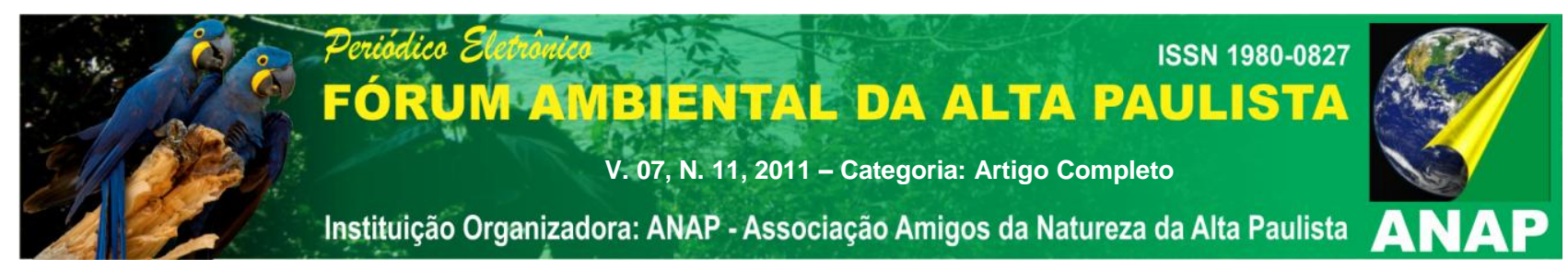

\section{Desenvolvimento \\ Área de Estudo}

A área de estudo foi uma Destilaria, localizada na região do Pontal do Paranapanema, no estado de São Paulo. A Destilaria, pioneira na fabricação de álcool no Brasil, foi a primeira destilaria autônoma a ser implantada no início do Pró-álcool, tendo iniciado suas atividades em 1978, tendo passado, portanto, por todas as dificuldades inerentes ao desenvolvimento da nova tecnologia que se iniciava no País.

Mantendo uma política de constante preocupação com o meio ambiente, foi uma das primeiras unidades a implantar sistema de aplicação de vinhaça nos canaviais, sempre de maneira racional, sem a utilização de áreas de sacrifício ou de super dosagens. Ainda na década de 80 , fechou o circuito do sistema de lavagem de cana, eliminando o lançamento de cargas poluidoras nos corpos d' água. Em 1994 deu início a produção de açúcar demerara ou VHP (Very Hight Pol), no qual a principal análise é a pol, ou seja, açúcar polarizável, o qual é conhecido também por açúcar cru.

Atualmente, a usina mói 1.500 .000 toneladas de cana, com capacidade de produzir 126 milhões de litros de álcool e 105.000 toneladas de açúcar. Hoje a Destilaria gera aproximadamente 2.300 empregos diretos, o que contribui para o desenvolvimento do município o qual está inserida.

Esta usina acaba produzindo cerca de 318.000 toneladas de bagaço por safra, sendo que deste total são consumidas 246.000 toneladas. A usina possui instalados cinco turbo geradores de 7,6 MW, em sistema de cogeração, onde são gerados 4,6 MW, que são consumidos integralmente pela usina. Ou seja, não há excedente de energia, e todo o bagaço é queimado nas caldeiras de pressão $21 \mathrm{kgf} / \mathrm{cm}^{2}$ e temperatura de $300 \stackrel{\circ}{\circ} \mathrm{C}$.

\section{Metodologia}

Para o desenvolvimento do presente trabalho, inicialmente foi elaborada uma revisão bibliográfica, com o levantamento de informações em artigos, teses, dissertações, monografias e em órgãos públicos e privados sobre o tema e área da pesquisa do estudo.

A identificação e a avaliação dos aspectos e impactos ambientais associados às atividades é um dos pontos mais importantes do planejamento do sistema de gestão ambiental, pois, através dele são investigados todas as atividades e setores que podem gerar danos ambientais e à saúde ou segurança dos trabalhadores.

Um aspecto ambiental é definido na ISO 14.001 em sua referência normativa como um elemento das atividades, produtos ou serviços de uma 
organização que pode interagir com o meio ambiente sendo complementada por uma observação de que "um aspecto ambiental significativo é aquele que tenha ou que possa ter um impacto ambiental significativo". Significa dizer que é de responsabilidade da empresa, estabelecer conclusões sobre seus aspectos ambientais através da análise de cada processo e sua interface de influência, sobre o meio ambiente.

Desta forma, para o levantamento dos aspectos ambientais e impactos ambientais da Destilaria foi desenvolvido um conjunto sistemático sobre os fluxos de energia e material ligados à atividade industrial.

Para tanto, foram realizadas entrevistas com os supervisores de cada setor, visitação das instalações, averiguação das atividades por setor e uso da lista de verificação. Os resultados foram tabulados em uma planilha do Excel for Windows.

Esta metodologia permitiu a elaboração de fluxogramas para os processos e atividades setoriais da organização fornecendo as informações sobre as saídas de poluentes de cada atividade ou processo. A análise das saídas e de suas fontes geradoras constituiu a identificação dos aspectos ambientais da organização e seus respectivos impactos ambientais.

Ressalta-se que, o fluxograma das entradas e saídas do processo industrial foi elaborado e avaliado, considerando o consumo de matérias-primas, a geração de resíduos (poluição atmosférica, da água e do solo) e a saída dos produtos, de acordo com o fluxograma do processo produtivo de açúcar e álcool da Destilaria em estudo.

Após a identificação dos aspectos e impactos ambientais, foi realizada a classificação e avaliação dos mesmos. A norma NBR ISO 14001 não é prescritiva, não exige uma metodologia complexa e deixa sua definição a carga da empresa. Qualquer metodologia pode ser aceita, desde que demonstre coerência, lógica e consistência e, principalmente, que estabeleça critérios para distinguir aspectos significativos de não significativos. O estabelecimento de critérios para a análise dos aspectos e avaliação dos impactos é imprescindível, embora não seja totalmente eficaz para evitar a subjetividade.

Neste contexto, a metodologia adotada neste trabalho foi baseada em MOREIRA (2006) e apresenta alguma similaridade à maioria das metodologias adotadas pelas empresas que implantaram o sistema de gestão ambiental.

De acordo com a metodologia proposta por MOREIRA (2006) os impactos foram analisados quanto à natureza, relevância e aplicação dos requisitos legais (legislação ambiental), para obter-se a avaliação da significância. 


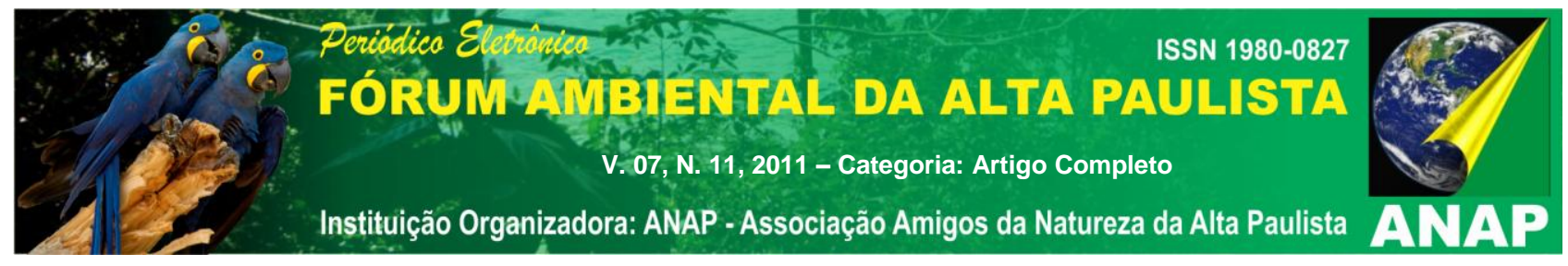

\section{Resultado e Análise}

Inicialmente obteve-se como resultado os fluxogramas das entradas e saídas do processo industrial de fabricação de açúcar e álcool, apresentados nas figuras 1, 2, 3, 4 e 5 .

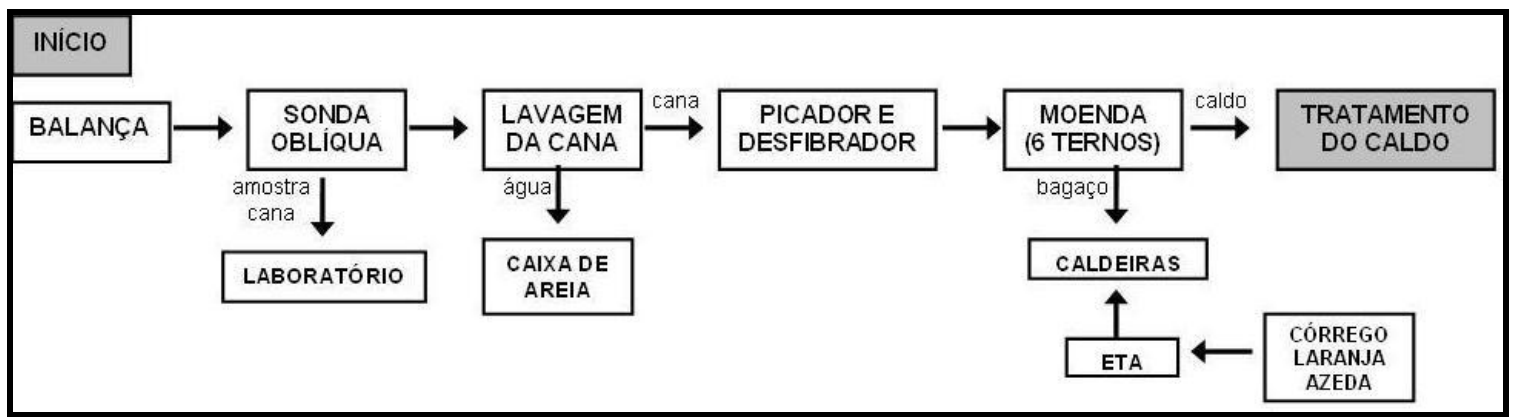

Figura 1. Fluxograma da amostragem de cana, recepção, moagem e captação de água.

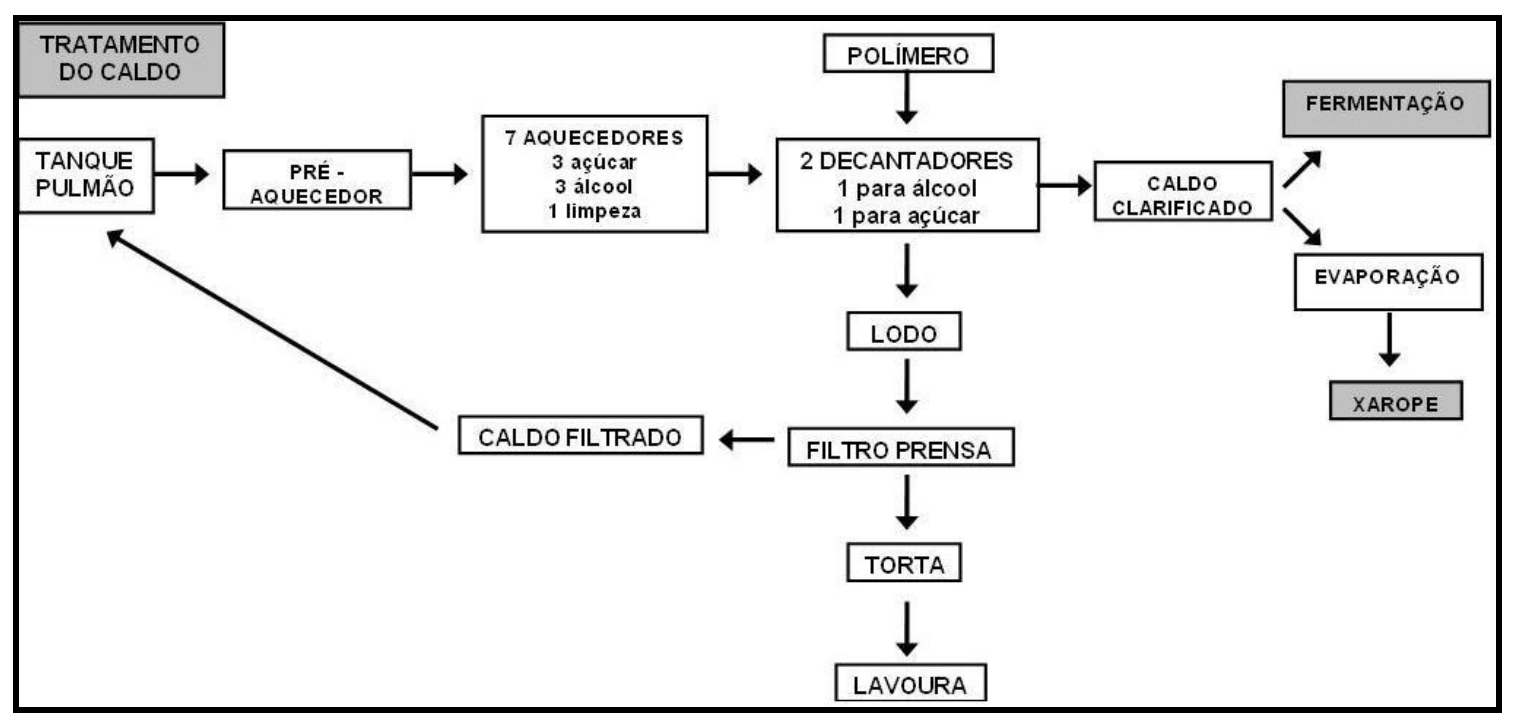

Figura 2. Fluxograma do tratamento do caldo.

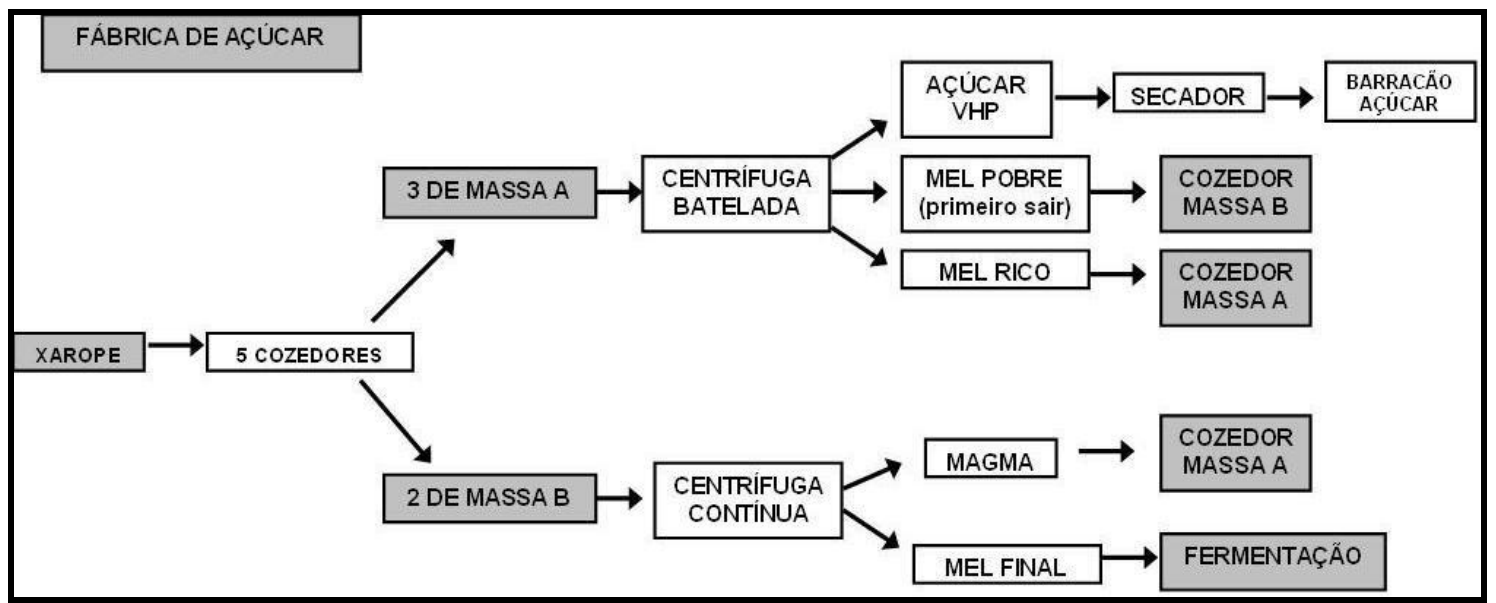

Figura 3. Fluxograma da Fábrica de açúcar. 

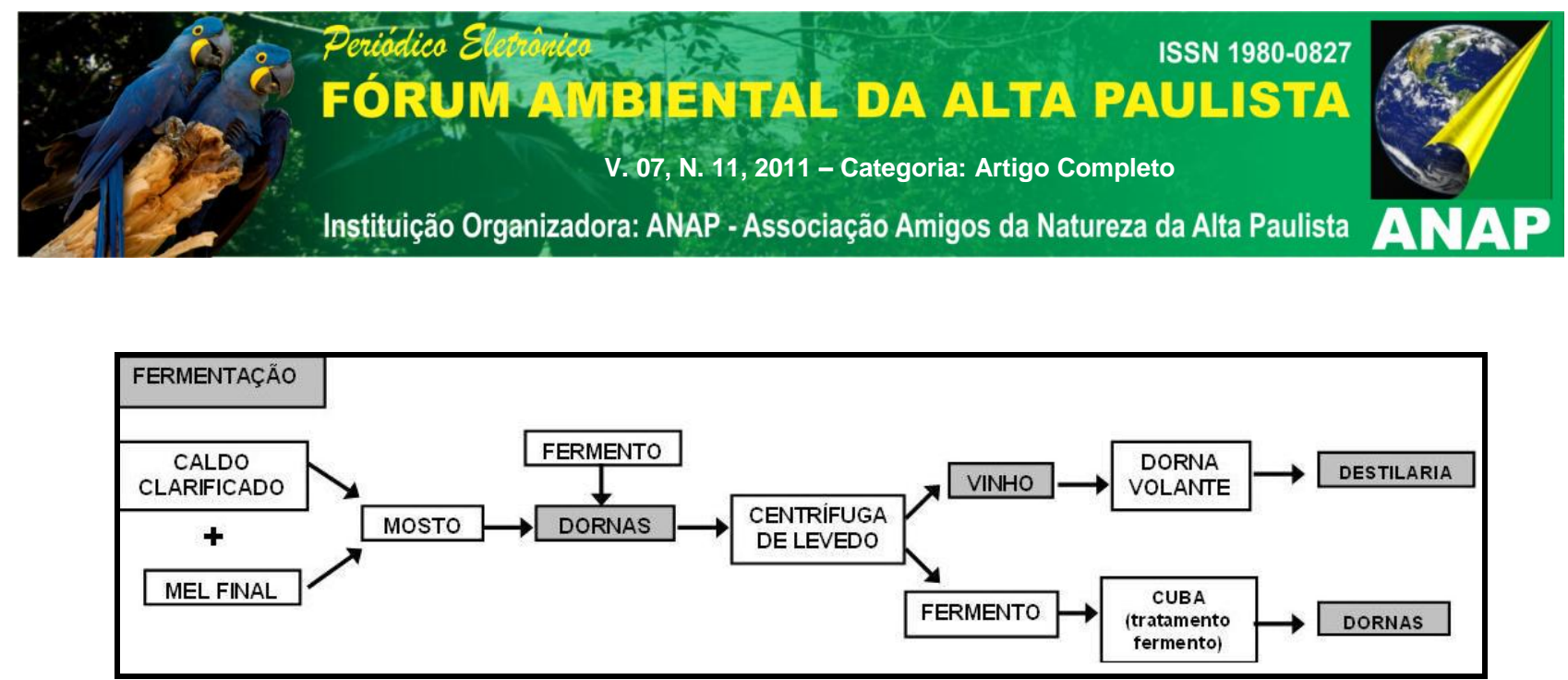

Figura 4. Fluxograma do processo de fermentação.

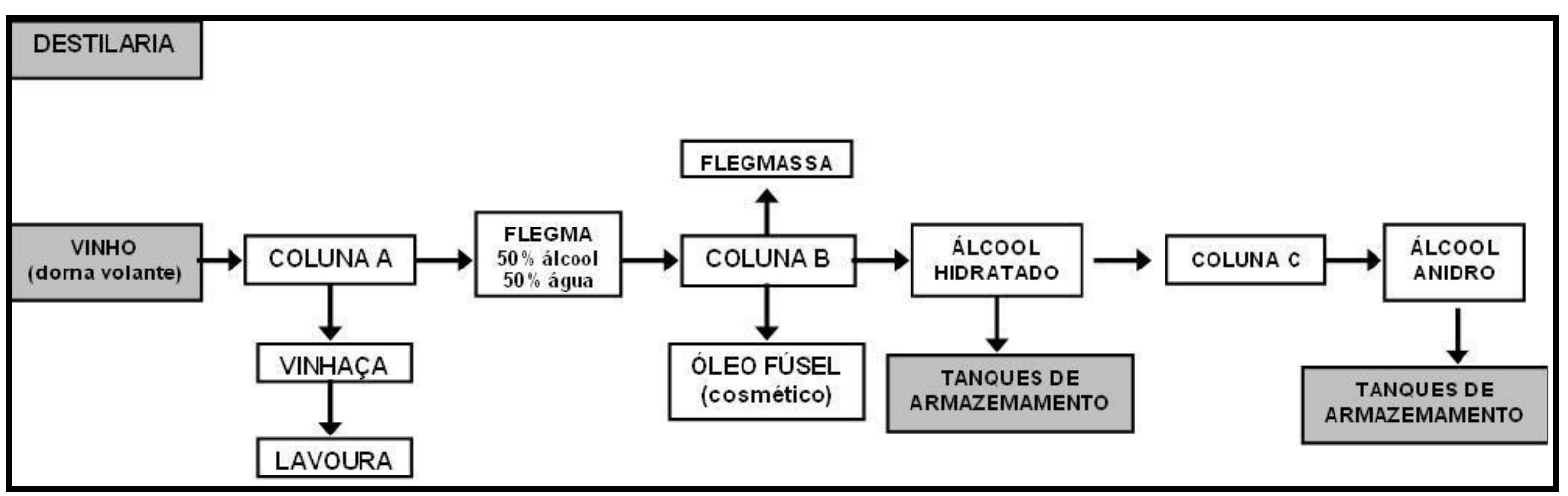

Figura 5. Fluxograma da Destilaria

Os resultados da identificação, classificação e avaliação dos aspectos e impactos ambientais do processo industrial da Destilaria, baseados nos fluxogramas (figura 1, 2, 3, 4 e 5) indicaram, após a avaliação da significância dos aspectos e impactos ambientais, que 24\% apresentaram significância desprezíveis, 44,6\% apresentaram significância moderada e 31,4\% apresentaram significância crítica.

\section{Conclusão}

Após a avaliação da significância dos aspectos e impactos ambientais, pode-se concluir que para os aspectos desprezíveis (24\%), deve-se manter a rotina estabelecida. Já para os aspectos moderados $(44,6 \%)$ e principalmente os críticos $(31,4 \%)$ de responsabilidade direta da empresa devem ser objeto de planos de ação.

Cada processo, portanto, deve merecer um plano de ação específico, em que seja definido o que fazer, como fazer, em que prazo realizar e sob responsabilidade de quem. Ao final de cada plano, é importante atualizar a avaliação de aspectos e impactos, pois a situação de controle poderá evoluir de razoável para satisfatória, por exemplo, alterando a classificação do aspecto. 


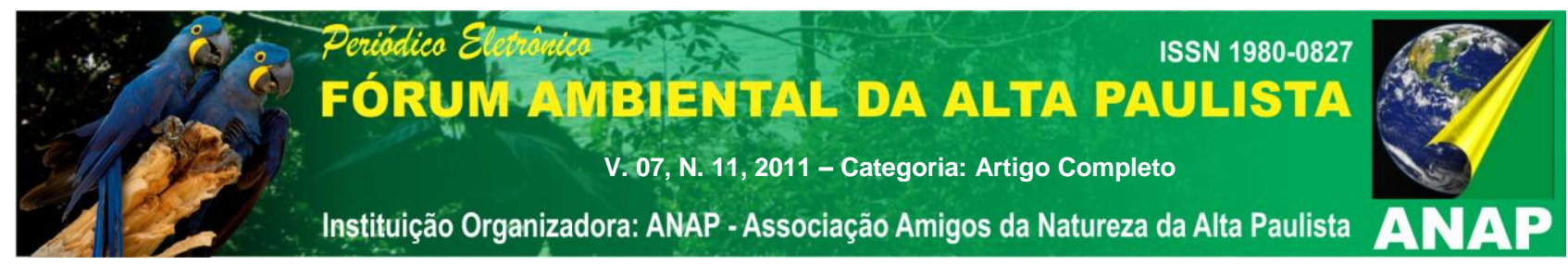

Em conclusão aos resultados apresentados, se apresenta uma listagem com algumas propostas para melhorias dos aspectos e impactos ambientais críticos no processo produtivo da ETH Bioenergia Destilaria Alcídia.

- Implantar o gerenciamento dos resíduos sólidos, ênfase na coleta seletiva;

- Monitorar as emissões dos veículos, adequando-as aos padrões legais, criar um programa interno de autofiscalização e correta manutenção quanto à emissão de fumaça preta e influenciar os fornecedores a adotar tal prática;

- Construir canaletas de contenção de combustíveis ou óleo dos caminhões;

- Uso de EPI's nos locais com grande concentração de caminhões;

- Uso de EPI's no painel de controle da sonda oblíqua;

- Implantar tratamento do efluente do laboratório;

- Implantar uma estação de tratamento de águas residuárias;

- Cobrir esteira de bagaço;

- Impermeabilizar o solo no local de depósito de bagaço;

- Desviar efluentes da canaleta que é direcionada para o córrego e fazer a limpeza desta canaleta que está totalmente obstruída;

- Considerar os riscos de maior gravidade e extensão em um plano de atendimento a emergência;

- Adequar o local das manutenções para contenção do óleo, utilizar o bagaço para absorção do óleo.

- Fazer uma bacia de contenção de óleo do transformador na captação de água;

- Evitar desperdício de cal pelo operador no hidratador;

- Mudar a válvula para não passar o vinho para a água, nas centrífugas de levedo, evitando o desperdício de água na pia;

- Construir um local específico para armazenamento de produtos químicos, com bacia de contenção;

- Elaborar uma política de gestão ambiental, ressaltando a organização;

- Impermeabilizar o solo próximo ao decantador de fuligem;

- Política/procedimento interno para economia e uso racional de água;

- Implantar um programa de educação ambiental;

- Pavimentação do solo de toda área industrial da usina;

- Passagem da água com óleo, gerada na moenda, na caixa separadora de água e óleo, para depois ser enviada para a caixa de decantação; 
Com a implantação das ações sugeridas, juntamente com um monitoramento contínuo do processo industrial, a empresa apresentará um bom desempenho ambiental, e alcançará o objetivo do sistema de gestão ambiental, o que possibilita com que a usina receba a certificação da NBR ISO 14001 (2004).

\section{REFERÊNCIAS}

ASSOCIAÇÃO BRASILEIRA DE NORMAS TÉCNICAS. NBR ISO14001: Sistemas da gestão ambiental - Requisitos com orientações para uso. Rio de Janeiro, 2004.

MOURA, Luiz A . A . de, Qualidade e Gestão Ambiental, sugestões para implantação das normas ISO14.000 nas empresas. $2^{\circ}$ ed., São Paulo, Juarez Oliveira, 2.000.

MOREIRA, M. S., Estratégia e Implantação do Sistema de Gestão Ambiental (Modelo ISO 14000). 3ํe ed., 2006.

DA SILVA SALLES, L. Elementos para o planejamento ambiental do complexo agroindustrial sucroalcooleiro no Estado de São Paulo: conceitos, aspectos e métodos. DISSERTAÇÃO DE MESTRADO, EESC USP, 1993.

CARVALHO, G. R.; OLIVEIRA, C. de. O setor sucroalcooleiro em perspectiva. Campinas: Embrapa Monitoramento por Satélite, 2006. 18 p., il. (Circular Técnica, 10).

MONÉA, N. M. A Legislação ambiental no setor sucroalcooleiro do estado de São Paulo como requisito da certificação ambiental ISO 14001. 2008. Especialização em Gestão Ambiental - Centro Universitário Barão de Mauá, Ribeirão Preto.

SÁNCHEZ, L. E; Avaliação de Impacto Ambiental: Conceitos e Métodos. São Paulo: Oficina de Textos, 2006.

\section{AGRADECIMENTO}

A Destilaria pela oportunidade de realização deste trabalho. 